\title{
Understanding Good Irrigation and Fertilization Behaviors Among Households Using Landscape Design Features $^{1}$
}

\author{
Anil Kumar Chaudhary and Laura A. Warner ${ }^{2}$
}

\section{Abstract}

With increasing concerns over water resources in Florida, Extension can target households with irrigated landscapes to encourage practices that protect water quality and quantity. We used landscape design features from 2,100 Florida households to segment households into subgroups to show how they may have different educational needs. Data analysis revealed two distinct subgroups based on landscape design features: the water-conserving landscape maximalists and the conservation-ambivalent landscape minimalists. Comparison of the two groups revealed households in the water-conserving landscape maximalists subgroup had higher personal obligation, more social support, stronger perceived behavioral control, and more engagement in water protection behaviors compared to conservation-ambivalent landscape minimalists households. Extension professionals can use the connection between diverse landscape design features and water protection behaviors to encourage good irrigation and fertilizer practices when they target these types of households for education.

\section{Introduction}

Floridians are facing critical issues regarding water quality and quantity, which appears in low water levels and impaired water in many of the state's water bodies (Leal, Rumble, \& Lamm, 2015; Lamm, Lamm, \& Carter, 2015; Marella, 2014; United States Environmental Protection Agency, 2017). Impacts on water resources can be reduced by changing water use and fertilization behaviors. Households with irrigated landscapes are an important target audience group because they have the potential to promote water protection if they can change some of their landscape management behaviors (Kumar Chaudhary, \& Warner, 2017; Martini, Nelson, Hobbie, \& Baker, 2015; Warner, Kumar Chaudhary, Rumble, Lamm, \& Momol, 2017). Statewide water protection programs conducted by UF/IFAS Extension promote effective fertilization and landscape water use among Floridians (UF/IFAS, 2011). Audience segmentation can be used to divide target audiences into subgroups using specific characteristics that may affect adoption of a specific behavior (Newton, Newton, Turk, \& Ewing, 2013; Warner, Lamm, Martin, Rumble, \& Momol, 2016). There is a potential for UF/IFAS Extension to further improve educational programming efforts that promote water protection behaviors by segmenting Florida households into meaningful subgroups.

1. This document is AEC630, one of a series of the Agricultural Education and Communication Department, UF/IFAS Extension. Original publication date January 2018. Visit the EDIS website at http://edis.ifas.ufl.edu.

2. Anil Kumar Chaudhary, former graduate student, Department of Agricultural Education and Communication; and Laura A. Warner, assistant professor, Department of Agricultural Education and Communication; UF/IFAS Extension, Gainesville, FL 32611. 


\section{Using Landscape Design Features to Segment Households to Guide Water Protection Behaviors}

Home landscapes in Florida's urban areas are important places where residents have opportunities to interact with nature and take action to protect the state's water resources. To make these interactions most enjoyable, residents choose the composition of their landscape based on their personal preferences (e.g., pollinator attracting plants, fruit trees, turfgrass; Shahli, Hussain, Tukiman, \& Zaidin, 2014). Considering the importance of landscape design features showcasing interaction with nature, Extension professionals can use landscape design features to segment residents into meaningful subgroups to promote water protection behaviors. The purpose of the study reported here was to determine if landscape design features related to good irrigation and fertilizer behaviors.

\section{Understanding How Landscape Design Features Can Define Household Types}

Households are more likely to adopt good irrigation and fertilization behaviors when they have strong social support, high internal personal obligation, positive attitudes, and high perceived ability to adopt good irrigation and fertilization practices (Ajzen, 1991). We surveyed Florida households that used landscape irrigation to learn about their:

- landscape design features (such as turfgrass, shade trees, ornamental plants, and palm trees),

- current engagement and future intent to engage in good irrigation and fertilization behaviors,

- personal obligation and social support to engage in good irrigation and fertilization behaviors,

- attitudes towards good irrigation and fertilization behaviors, and

- perceived ability to use good irrigation and fertilization practices among households (Kumar Chaudhary \& Warner, 2017).

A total of 2,100 Florida households provided a complete response. We used cluster analysis to segment Florida households based on their landscape design features. Using landscape design features, we found two meaningful subgroups which we named the waterconserving landscape maximalists $(n=804 ; 38.2 \%)$ and the conservation-ambivalent landscape minimalists $(n=1,296$; $61.7 \%$; Kumar Chaudhary \& Warner, 2017). A summary of the results follows.

- Landscape design features: The water-conserving landscape maximalists subgroup households have more landscape design features in their landscape compared to the conservation-ambivalent landscape minimalists subgroup. The most and least common landscape design features among both subgroups were shade trees and drought-tolerant plants, respectively.

- Attitudes: Households in both subgroups have positive attitudes towards good irrigation and good fertilization behaviors, and subgroups' attitudes were not different.

- Current engagement and future intent to engage in water protection behaviors: Current engagement and future intent to engage in good fertilization and irrigation behaviors is significantly higher among the waterconserving landscape maximalists subgroup compared to the conservation-ambivalent landscape minimalists subgroup.

- Social norms: Households in the water-conserving landscape maximalists subgroup have more social support to engage in good irrigation and fertilization behaviors compared to the conservation-ambivalent landscape minimalists subgroup.

- Personal norms: Compared to the water-conserving landscape maximalists subgroup, households in the diversity-prone water protectors subgroup feel a stronger sense of personal obligation to engage in good irrigation and fertilization behaviors.

- Perceived behavioral control: Water-conserving landscape maximalists subgroup households feel they have greater ability to use good irrigation and fertilization practices compared to conservation-ambivalent landscape minimalists subgroup households.

Both subgroups were different in terms of their landscape design features, personal and social norms, control to engage in water protection behaviors, and current and future intent to engage in good irrigation and fertilization behaviors. Overall, this means those who have a more diverse landscape are more likely to use water and fertilizer in responsible ways in the landscape. The biggest practical differences among subgroups was their current engagement in irrigation behaviors, which indicated that diversity in landscape design features is more closely associated to water conservation behaviors compared to water quality protection behaviors. 
Essentially, greater value placed on water resources materializes as more complex landscapes that require more work. It is likely the water-conserving landscape maximalists are the individuals who attend Extension programs. Thus, local programs should develop strategies to target the conservation-ambivalent landscape minimalists and engage them in water protection activities.

People who prefer greater diversity of landscape design features may be more engaged in protecting water quality and quantity. Alternatively, people who are more engaged in protecting water resources are more likely to diversify their landscape design features. While more research is needed to explore this relationship, we know having more diverse landscapes is related to more social support, personal obligation, and more control among households to engage in good irrigation and fertilization behaviors (Kumar Chaudhary \& Warner, 2017).

\section{How to Use this Information}

Extension professionals with a focus on water protection should consider:

- Promoting diversity in landscape design features, such as more landscape design features that relate to water protection behaviors. The Florida-Friendly Landscaping ${ }^{\mathrm{Tm}}$ (FFL; http://ffl.ifas.ufl.edu/index.html) program provides excellent resources to promote diversity in the landscape.

- Promoting more complex behaviors (e.g., installation of soil moisture sensors) among households with diverse landscapes. Because households with diverse landscape design features have higher current engagement and future intent to engage in good irrigation and fertilization behaviors, they are more receptive to complex water protection behaviors.

- Promoting diverse landscapes, as diverse landscapes not only promote water protection behaviors, but may also lead to strong norms and higher perceived ability to engage in water protection behaviors.

- Designing simple messages requiring less effort to change behavior for households with sparse landscape design features, and complex messages that require more effort to change a fertilization or irrigation behavior for households with diverse landscape design features.

\section{Conclusions}

Segmenting households with irrigated landscapes based on their landscape design features provides an opportunity to promote water protection behaviors. Households with diverse landscape features are more engaged in protecting water resources and may be more receptive to adopting new technologies and practices, while those with few landscape features may have a greater capacity to conserve. Hence, Extension professionals can target the two audiences in different ways to promote good irrigation and fertilization behaviors. Further research may be useful in understanding the differences between the groups and how Extension programs can appeal to their unique characteristics.

\section{Acknowledgements}

The authors thank the University of Florida Center for Landscape Conservation and Ecology (http://clce.ifas.ufl. edu) for supporting the research presented in this publication. We also thank our anonymous reviewers for providing valuable input on a previous draft.

\section{References}

Ajzen, I. (1991). The theory of planned behavior. Organizational Behavior and Human Decision Processes, 50(2), 179-211.

Kumar Chaudhary, A., \& Warner, L. A. (2017). Segmenting households using landscape design features to understand irrigation and fertilization behaviors. Journal of Extension. Manuscript submitted for publication.

Lamm, K. W., Lamm, A. J., \& Carter, H. S. (2015). Bridging water issue knowledge gaps between the general public and opinion leaders. Journal of Agricultural Education, 56(3), 146-161. doi:10.5032/jae.2015.03146

Leal, A., Rumble, J., \& Lamm, A. J. (2015). Setting the agenda: Exploring Floridian's perceptions of water quality and quantity issues. Journal of Applied Communications, 99(3), 53-67. Retrieved from http://newprairiepress.org/ cgi/viewcontent.cgi article $=1058 \&$ context $=$ jac

Marella, R. (2014). Water withdrawals, use, and trends in Florida, 2010. U.S. Geological Survey. Retrieved from http://pubs.usgs.gov/sir/2014/5088/pdf/sir2014-5088.pdf

Martini, N. F., Nelson, K. C., Hobbie, S. E., \& Baker, L. A. (2015). Why "feed the lawn"? Exploring the influences on residential turf grass fertilization in the Minneapolis-Saint Paul metropolitan area. Environment and Behavior, 47(2), 158-183. doi:10.1177/0013916513492418

Newton, J., J. Newton, F., Turk, T., \& T. Ewing, M. (2013). Ethical evaluation of audience segmentation in social marketing. European Journal of Marketing, 47(9), 1421-1438. doi:10.1108/EJM-09-2011-0515uf libr 
Shahli, F. M., Hussain, M. R. M., Tukiman, I., \& Zaidin, N. (2014). The importance aspects of landscape design on housing development in urban areas. APCBEE Procedia, 10, 311-315. doi:10.1016/j.apcbee.2014.10.058

United States Environmental Protection Agency. (2017). Florida water quality assessment report. Retrieved from https://ofmpub.epa.gov/waters10/attains_state. control?p_state $=\mathrm{FL}$

University of Florida Institute of Food and Agricultural Sciences [UF/IFAS]. (2011). Shaping solutions for Florida's future: The University of Florida extension roadmap 20132023. University of Florida. Retrieved from http://pdec.ifas. ufl.edu/roadmap/FloridaExtensionRoadmap_2013-2023. pdf

Warner, L. A., Kumar Chaudhary, A.; Rumble, J. N., Lamm, A. J., Momol, E. (2017). Using audience segmentation to tailor residential irrigation water conservation programs. Journal of Agricultural Education, 58(1), 313-333.

doi:10.5032/jae.2017.01313

Warner, L. A., Lamm, A., Martin, E., Rumble, J., \& Momol, E. (2016). Encouraging landscape water-conservation behaviors \#5: Segmenting the audience based on HOA status. Gainesville: University of Florida Institute of Food and Agricultural Sciences (AEC584). Retrieved from http://edis. ifas.ufl.edu/pdffiles/WC/WC24600.pdf 